\title{
Accuracy of the Ventilator Automated Displayed Respiratory Mechanics in Passive and Active Breathing Conditions: A Bench Study
}

\author{
Ehab G Daoud, Reynaldo Katigbak, and Marcus Ottochian
}

\begin{abstract}
BACKGROUND: New-generation ventilators display dynamic measures of respiratory mechanics, such as compliance, resistance, and auto-PEEP. Knowledge of the respiratory mechanics is paramount to clinicians at the bedside. These calculations are obtained automatically by using the least squares fitting method of the equation of motion. The accuracy of these calculations in static and dynamic conditions have not been fully validated or examined in different clinical conditions or various ventilator modes. METHODS: A bench study was performed by using a lung simulator to compare the ventilator automated calculations during passive and active conditions. Three clinical scenarios (normal, COPD, and ARDS) were simulated with known compliances and resistance set per respective condition: normal (compliance $50 \mathrm{~mL} / \mathrm{cm}_{2} \mathrm{O}$, resistance $10 \mathrm{~cm} \mathrm{H} \mathrm{H}_{2} \mathrm{O} / \mathrm{L} / \mathrm{s}$ ), COPD (compliance $60 \mathrm{~mL} / \mathrm{cm} \mathrm{H}_{2} \mathrm{O}$, resistance $22 \mathrm{~cm} \mathrm{H}_{2} \mathrm{O} / \mathrm{L} / \mathrm{s}$ ), and ARDS (compliance $30 \mathrm{~mL} / \mathrm{cm} \mathrm{H}_{2} \mathrm{O}$, and resistance $\left.13 \mathrm{~cm} \mathrm{H} \mathrm{H}_{2} \mathrm{O} / \mathrm{L} / \mathrm{s}\right)$. Each scenario was subjected to 4 different muscle pressures $\left(\mathrm{P}_{\text {mus }}\right)$ : $0,-5,-10$, and $-15 \mathrm{~cm} \mathrm{H}_{2} \mathrm{O}$. All the experiments were done using adaptive support ventilation. The resulting automated dynamic calculations of compliance and resistance were then compared based on the clinical scenarios. RESULTS: There was a small bias (average error) and level of agreement in the passive conditions in all the experiments; however, these errors and levels of agreement got progressively higher proportional to the increased $P_{\text {mus }}$. There was a strong positive correlation between $\mathbf{P}_{\text {mus }}$ and compliance measured as well as a strong negative correlation between $\mathbf{P}_{\text {mus }}$ and resistance measured. CONCLUSIONS: Automated displayed calculations of respiratory mechanics were not dependable or accurate in active breathing conditions. The calculations were clinically more reliable in passive conditions. We propose different methods of calculating $\mathbf{P}_{\text {mus }}$, which, if incorporated into the calculations, would improve the accuracy of respiratory mechanics made via the least squares fitting method in actively breathing conditions. [Respir Care 2019;64(12):1555-1560. (C) 2019 Daedalus Enterprises] Key words: least squares fitting method; lung model; muscle pressure; respiratory mechanics; simulation models.
\end{abstract}

\section{Introduction}

Monitoring of respiratory mechanics at the bedside during mechanical ventilation is of utmost importance to the clinician and the patient. Modern ventilators offer a variety of waveforms, loops, graphics, and automated calculations

\footnotetext{
Dr Daoud is affiliated with the Respiratory Care Program, Kapiolani Community College, Honolulu, Hawaii, and John A Burns School of Medicine, University of Hawaii Honolulu, Hawaii. Mr Katigbak is affiliated with Kaiser Permanente Respiratory Department, Kaiser Permanente, Honolulu, Hawaii. Dr Ottochian is affiliated with the Shock Trauma Center, University of Maryland, Baltimore, Maryland.
}

The authors have disclosed no conflicts of interest. to guide the clinicians at the bedside. It is invaluable to assess the respiratory mechanics quickly, easily, accurately differentiate various diseases processes, assess progress or regress during therapy, and to optimize mechanical ventilatory support. ${ }^{1}$ Traditionally, static measurements of total respiratory compliance, resistance, and auto-PEEP have been obtained by using the end-inspiratory and end-expiratory holding maneuvers during volume-controlled continuous mandatory ventilation with constant flow. ${ }^{2}$ These

Correspondence: Ehab G Daoud MD, Kapiolani Community College, 4303 Diamond Head Rd, Honolulu, HI 96816.E-mail: ehab_daoud@ hotmail.com.

DOI: $10.4187 /$ respcare.06422 
maneuvers are easy to do in the passive patient, that is, with no respiratory effort, but usually become difficult and inaccurate in the active patient with spontaneous respiratory efforts.

As an alternative to these static measurements, a computed method evolved in 1990 by Gillard et al, ${ }^{3}$ which was proposed to be accurate and provide a rapid approach to respiratory mechanics. This method is known as the linear least squares fitting method. It is a computed regression analysis derived from the respiratory equation of motion, which allows for breath-by-breath display of respiratory mechanics in any mode of ventilation without any holding maneuvers or certain flow pattern. ${ }^{1,4}$ The method attempts to fit the equation of motion to the measured pressure, volume, and flow data to calculate respiratory mechanics. However, the pressure data will be distorted by muscle pressure $\left(\mathrm{P}_{\text {mus }}\right)$ generated during active breathing, which results in erroneous calculated values for resistance and compliance. The simplified equation:

$$
\mathrm{P}_{\text {Total }}=\mathrm{P}_{\mathrm{vent}}+\mathrm{P}_{\mathrm{mus}}=\mathrm{V}_{\mathrm{T}} / \mathrm{C}_{\mathrm{RS}}+\mathrm{R}_{\mathrm{aw}} \times \dot{\mathrm{V}}+
$$
(PEEP + PEEPi)

Where $\mathrm{P}_{\text {Total }}$ is the total pressure required to move tidal volume, $\mathrm{P}_{\text {vent }}$ is the airway pressure, $\mathrm{P}_{\text {mus }}$ is the patient's muscle pressure, all in $\mathrm{cm}_{2} \mathrm{O} ; \mathrm{V}_{\mathrm{T}}$ is the tidal volume in $\mathrm{mL} ; \mathrm{C}_{\mathrm{RS}}$ is respiratory system compliance in $\mathrm{mL} / \mathrm{cm} \mathrm{H}_{2} \mathrm{O}$; $\mathrm{R}_{\mathrm{aw}}$ is airway resistance in $\mathrm{cm} \mathrm{H}_{2} \mathrm{O} / \mathrm{L} / \mathrm{s} ; \dot{\mathrm{V}}$ is flow in $\mathrm{L} / \mathrm{s}$; and PEEPi is the intrinsic PEEP in $\mathrm{cm}_{2} \mathrm{O}$.

Some new ventilator manufacturers have incorporated these automated calculation displays to simplify the process at the bedside. These calculations, however, were scrutinized by some investigators. ${ }^{5,6}$ The least squares fitting method leads to gross underestimation of the respiratory system resistance and overestimation of the respiratory system compliance. Specifically, these errors are due to the effect of $\mathrm{P}_{\text {mus }}$ decreasing $\mathrm{P}_{\text {vent }}$ during volumecontrolled continuous mandatory ventilation or increasing volume and flow during pressure-controlled continuous mandatory ventilation compared with passive inflation.

Given the ease and the availability of these calculations on new ventilator displays, clinicians may be widely misled regarding the real respiratory mechanics of their patients if these numbers were to prove inaccurate. This, in turn, can lead to misdiagnosis and mismanagement of such patients. Our hypothesis of the current descriptive study is that the ventilator automated calculations of respiratory mechanics are inaccurate during active breathing conditions. We attempted to demonstrate the magnitude of errors displayed by the ventilators when calculating mechanics for passive and active breathing conditions by using realistic simulation models. We discussed the reasons beyond these inaccuracies and offered some alternative ways of improving these errors.

\section{QUICK LOOK}

\section{Current knowledge}

New-generation ventilators display respiratory mechanics (compliance, resistance, and auto-PEEP) as calculated by the least squares fitting method for the equation of motion. This continuous display is intended to provide quick, easy understanding of patients' conditions in any ventilator mode and without any additional maneuvers.

\section{What this paper contributes to our knowledge}

This current study showed that the displayed respiratory mechanics were not accurate or reliable in actively breathing conditions. Clinicians should not base any ventilator adjustments or conclusions based solely on the ventilator displayed respiratory mechanics.

\section{Methods}

We compared the ventilator calculated compliance and resistance with known parameters for these respective values set on a simulated lung model. The experiment was conducted with a lung simulator (ASL 5000, IngMar Medical, Pittsburgh, Pennsylvania). The "lung model" used was one compartment model. Three clinical scenarios were constructed as follows: normal lung, COPD, and ARDS, with compliances of 50,60 , and $30 \mathrm{~mL} / \mathrm{cm} \mathrm{H}_{2} \mathrm{O}$, respectively, and resistances of 10,20 , and $13 \mathrm{~cm} \mathrm{H}_{2} \mathrm{O} / \mathrm{L} / \mathrm{s}$, respectively (Table 1 ). The parameters used were in concordance with Arnal et $\mathrm{al}^{7}$ recently published parameters of simulation.

The accuracy of the simulated lung mechanics were validated in each scenario by using the traditional endinspiratory and end-expiratory holding maneuvers in volume-controlled continuous mandatory ventilation with a constant flow in the passive condition before the experiment to confirm the set parameters. Each scenario was subdivided into 4 experiments. First, the passive condition with zero breathing frequency and zero $\mathrm{P}_{\text {mus }}$. The second, third, and fourth experiments were the simulated active conditions "effort model" with a spontaneous respiratory rate of 15 and 3 different maximum values of $\mathrm{P}_{\text {mus }}$ of $-5,-10$, and $-15 \mathrm{~cm} \mathrm{H}_{2} \mathrm{O}$, respectively. All spontaneous breaths were sinusoidal in pattern (pre-programmed in the Active Servo Lung with $10 \%$ rise, $5 \%$ hold, and $10 \%$ release while exhalation was passive. All experiments were conducted by using the adaptive support ventilation mode on a Hamilton-G5 ventilator (Hamilton Medical AG, Bonaduz, Switzerland). The adaptive support ventilation mode is considered a pressure-controlled intermittent 
Table 1. Statistics By Using the Paired $t$-Test Between Lung Model (test) and Each Experiment in Normal, COPD, and ARDS Lungs

\begin{tabular}{lllll}
\hline \hline Parameter* & $\begin{array}{c}\text { Compliance } \\
\left(\mathrm{mL} / \mathrm{cm} \mathrm{H}_{2} \mathrm{O}\right)\end{array}$ & $P$ & $\begin{array}{c}\text { Resistance } \\
\left(\mathrm{cm} \mathrm{H} \mathrm{H}_{2} \mathrm{O} / \mathrm{L} / \mathrm{s}\right)\end{array}$
\end{tabular}$\quad P$

Normal

Test

0

$-5$

$-10$

$-15$

COPD

Test

0

$-5$

$-10$

$-15$

ARDS

Test

0

$-5$

$-10$

$-15$

Data are presented as mean $\pm \mathrm{SD}$

* 0 is passive effort model with no muscle pressure $\left(\mathrm{P}_{\text {mus }}\right) ;-5,-10,-15$ are the $\mathrm{P}_{\text {mus }}$ of

each experiment in the active effort model, expressed as $\mathrm{cm} \mathrm{H}_{2} \mathrm{O}$.

mandatory ventilation with optimal and intelligent targeting scheme, in which the ventilator automatically adjusts the targets of the ventilatory pattern to either minimize or maximize some overall performance characteristic. ${ }^{8}$ The studied mode and ventilator calculates the compliance and resistance by using the linear regression method explained in the introduction.

Settings used were for a male patient, height $170 \mathrm{~cm}$, with $100 \%$ minute ventilation support. Fifty breaths were analyzed in each experiment (5 per minute for $10 \mathrm{~min}$ ). Only the spontaneous active breaths were included in the active groups. We were able to only analyze the compliances and resistances because the ventilator did not display the auto-PEEP in most of the active conditions.

To quantify the agreement between the parameters (compliance and resistance) set on the simulated lung and those displayed by the ventilator, we applied the Bland-Altman method and obtained the mean bias and limits of agreement for each one of the single experiments. Before each analysis, we performed a Kolmogorov-Smirnov test to confirm the normal distribution of the differences between values. This is a pre-requisite for the use of the BlandAltman method. The analysis was carried out by using $\mathrm{R}$ (version 3.5.2) and RStudio (version 1.1.463). The Pearson correlation coefficient was used to test the relationship between the $\mathrm{P}_{\text {mus }}$ and the resultant compliances and resistances in each clinical scenario.
Table 2. Bland-Altman Analysis of Compliance Between Simulated Lung and Ventilator Calculations: Each Experiment in Normal, COPD, and ARDS Lungs

\begin{tabular}{|c|c|c|c|}
\hline Parameter* & $\begin{array}{l}\text { Mean Bias } \\
\text { (average error) } \\
\left(\mathrm{mL} / \mathrm{cm} \mathrm{H}_{2} \mathrm{O}\right)\end{array}$ & $\begin{array}{l}\text { Lower LOA } \\
\left(\mathrm{mL} / \mathrm{cm} \quad \mathrm{H}_{2} \mathrm{O}\right)\end{array}$ & $\begin{array}{c}\text { Upper LOA } \\
\left(\mathrm{mL} / \mathrm{cm} \quad \mathrm{H}_{2} \mathrm{O}\right)\end{array}$ \\
\hline \multicolumn{4}{|l|}{ Normal } \\
\hline 0 & -0.6 & -0.9 & -0.3 \\
\hline-5 & 8.0 & 4.9 & 11.1 \\
\hline-10 & 24.8 & 23.8 & 25.8 \\
\hline-15 & 36.6 & 34.6 & 38.7 \\
\hline \multicolumn{4}{|l|}{ COPD } \\
\hline 0 & 0.9 & 0.1 & 1.8 \\
\hline-5 & 5.6 & 4.4 & 6.9 \\
\hline-10 & 16.9 & 14.4 & 19.3 \\
\hline-15 & 29.8 & 26.9 & 32.5 \\
\hline \multicolumn{4}{|l|}{ ARDS } \\
\hline 0 & -0.2 & -0.4 & -0.1 \\
\hline-5 & 14.5 & 13.5 & 15.4 \\
\hline-10 & 21.4 & 20.5 & 22.3 \\
\hline-15 & 32.8 & 31.4 & 34.1 \\
\hline \multicolumn{4}{|c|}{$\begin{array}{l}* 0 \text { is passive effort model with no muscle pressure }\left(\mathrm{P}_{\mathrm{mus}}\right) ;-5,-10,-15 \text { are the } \mathrm{P}_{\text {mus }} \text { of } \\
\text { each experiment in the active effort model, expressed as } \mathrm{cm} \mathrm{H} \mathrm{H}_{2} \mathrm{O} \text {. } \\
\mathrm{LOA}=\text { level of agreement } \\
\mathrm{P}_{\text {mus }}=\text { muscle pressure }\end{array}$} \\
\hline
\end{tabular}

\section{Results}

The results are summarized in Tables 2 and 3. In all 3 scenarios, the ventilator-displayed compliances and resistances showed a small mean bias and a narrow limits of agreement for the passive effort model $\left(\mathrm{P}_{\text {mus }}=0 \mathrm{~cm} \mathrm{H_{2 }} \mathrm{O}\right)$ compared with the active effort model $\left(\mathrm{P}_{\text {mus }}>0 \mathrm{~cm} \mathrm{H}_{2} \mathrm{O}\right)$ The mean bias progressively increased and the limits of agreement progressively widened with the increase in $\mathrm{P}_{\text {mus }}$ under the active effort model. There was a strong statistical positive correlation between the $\mathrm{P}_{\text {mus }}$ and the respiratory compliances $(\mathrm{R}=0.99$ in normal, 0.99 in ARDS, and 0.98 in COPD) (Fig. 1). Similarly, there was a strong statistical negative correlation between the $\mathrm{P}_{\text {mus }}$ and the resistances $(\mathrm{R}=-0.93$ in normal, -0.98 in ARDS, and -0.98 in COPD) (Fig. 2). The auto-PEEP could not be obtained from the ventilator in any of the actively breathing scenarios.

\section{Discussion}

As explained above, some modern-generation ventilators use a computed multiple linear regression analysis called the linear least squares fitting method to fit the equation to the data to derive values for the equation parameters: respiratory system compliance, respiratory system resistance, and the total PEEP. The equation is displayed above in introduction section and is explained in 


\section{Accuracy of Ventilator Automated Respiratory Mechanics}

Table 3. Bland-Altman Analysis of Resistance Between Simulated Lung and Ventilator Calculations: Each Experiment in Normal, COPD, and ARDS Lungs

\begin{tabular}{|c|c|c|c|}
\hline Parameter* & $\begin{array}{l}\text { Mean Bias } \\
\text { (average error) } \\
\left(\mathrm{cm} \mathrm{H}_{2} \mathrm{O} / \mathrm{L} / \mathrm{s}\right)\end{array}$ & $\begin{array}{c}\text { Lower LOA } \\
\left(\mathrm{cm} \mathrm{H}_{2} \mathrm{O} / \mathrm{L} / \mathrm{s}\right)\end{array}$ & $\begin{array}{l}\text { Upper LOA } \\
\left(\mathrm{cm} \mathrm{H}_{2} \mathrm{O} / \mathrm{L} / \mathrm{s}\right)\end{array}$ \\
\hline \multicolumn{4}{|l|}{ Normal } \\
\hline 0 & -0.5 & -1.5 & 0.5 \\
\hline-5 & -6.5 & -7.5 & -5.5 \\
\hline-10 & -9.5 & -10.5 & -8.5 \\
\hline-15 & -9.7 & -10.6 & -8.8 \\
\hline \multicolumn{4}{|l|}{ COPD } \\
\hline 0 & 1.1 & 0.6 & 1.5 \\
\hline-5 & -2.2 & -3.2 & -1.2 \\
\hline-10 & -9.5 & -10.5 & -8.5 \\
\hline-15 & -14.2 & -15.4 & -12.9 \\
\hline \multicolumn{4}{|l|}{ ARDS } \\
\hline 0 & -0.5 & -1.5 & 0.5 \\
\hline-5 & -5.8 & -7.2 & -4.3 \\
\hline-10 & -11 & -11 & -11 \\
\hline-15 & -12.6 & -13.6 & -11.6 \\
\hline \multicolumn{4}{|c|}{$\begin{array}{l}* 0 \text { is passive effort model with no muscle pressure }\left(\mathrm{P}_{\text {mus }}\right) ;-5,-10,-15 \text { are the } \mathrm{P}_{\text {mus }} \text { of } \\
\text { each experiment in the active effort model, expressed as } \mathrm{cm} \mathrm{H}_{2} \mathrm{O} . \\
\text { LOA = level of agreement } \\
\mathrm{P}_{\text {mus }}=\text { muscle pressure }\end{array}$} \\
\hline
\end{tabular}

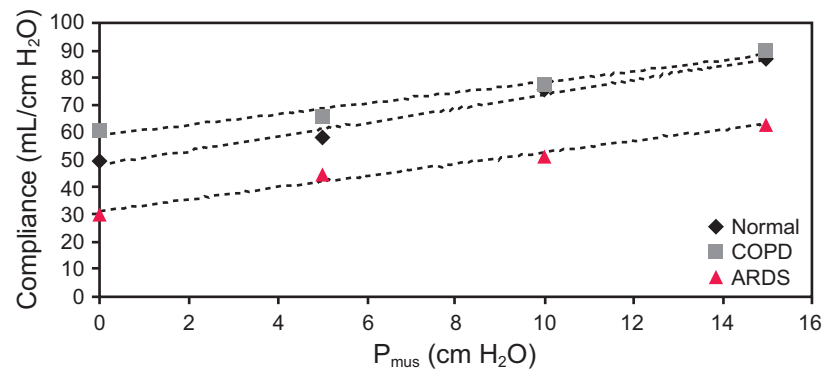

Fig. 1. Pearson correlation coefficient, showing a strong linear positive correlation between muscle pressure $\left(P_{\text {mus }}\right)$ and respiratory system compliance.

detail elsewhere ${ }^{9}$ The rationale for our finding was the missing $\mathrm{P}_{\mathrm{mus}}$ in the equation of motion during the respiratory cycle. The ventilator measures the airway pressure, volume, and flow, while assuming passive or zero $\mathrm{P}_{\text {mus }} \cdot{ }^{1}$

Now the questions that need to be answered are the following: can the ventilator measure the $\mathrm{P}_{\text {mus }}$ ? If yes, then can that measurement be incorporated or plugged into the equation of motion to give accurate measurements of the respiratory mechanics? There are multiple ways to calculate the $\mathrm{P}_{\text {mus }}$, which would require additional equipment, mainly esophageal balloon manometry. Given its many useful features, various new-generation ventilators are currently equipped with built-in ports to measure the esophageal pressures.

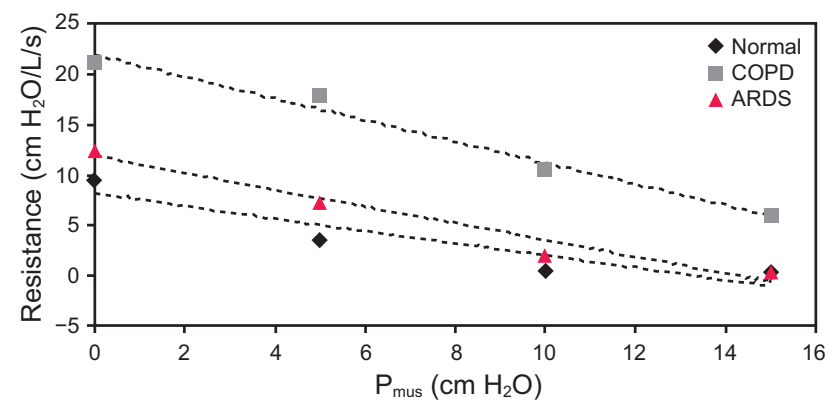

Fig. 2. Pearson correlation coefficient, showing a strong linear negative correlation between muscle pressure $\left(P_{\text {mus }}\right)$ and respiratory system resistance.

A brief summary of the equations are displayed below, detailed discussions of these equations are beyond the scope of this study and are explained elsewhere. The $\mathrm{P}_{\mathrm{mus}}$ is estimated to be the difference between the static recoil pressure of the relaxed chest wall $\left(\mathrm{P}_{\mathrm{cw}}, \mathrm{rel}\right)$ and the esophageal pressure $\left(\mathrm{P}_{\mathrm{es}}\right)$.

$\mathrm{P}_{\text {mus }}=\left(\mathrm{P}_{\mathrm{cw}}, \mathrm{rel}\right)-\mathrm{P}_{\mathrm{es}}$

This is discussed in detail by Akoumianaki et $\mathrm{al}^{10}$ in their review of this technology. A similar approach to estimate the $\mathrm{P}_{\text {mus }}$ also requires esophageal balloon manometry by using the rapid interrupter technique. ${ }^{11}$ This technique is used to calculate the pressure-time product. The equation is described as

$\left(\mathrm{P}_{\text {mus }}\right.$, occl $)=\left(\mathrm{P}_{\text {alv }}\right.$, occl $)-\left(\mathrm{P}_{\mathrm{el}}, \mathrm{rs}\right)$

Where $\mathrm{P}_{\text {mus }}$, occl is the $\mathrm{P}_{\text {mus }}$ during the occlusion maneuver; $\mathrm{P}_{\mathrm{alv}}$, occl is the alveolar pressure during the occlusion maneuver; and $\mathrm{P}_{\mathrm{el}}$, rs is the elastic pressure of the respiratory system. Another feasible and easy estimation of the $\mathrm{P}_{\text {mus }}$ would be the difference in esophageal pressure as a surrogate of pleural pressure $\left(\mathrm{P}_{\mathrm{pl}}\right)$ during the passive state and the active state if receiving same tidal volume and flow. ${ }^{12}$

$\mathrm{P}_{\text {mus }}=\mathrm{P}_{\mathrm{pl}}$ (passive) $-\mathrm{P}_{\mathrm{pl}}$ (active)

Although much less precise, the simple change of the esophageal pressure during inspiration during airway occlusion maneuver could be used as a bedside monitoring tool, as done in some sleep studies ${ }^{13}$ or during a weaning trial. ${ }^{14}$

A commercially available monitor, Patient Ventilator Interaction (PVI Monitor, YRT, Winnipeg, Manitoba, Canada), was designed in 2007 by Younes et al ${ }^{15}$ to monitor and improve patient-ventilator interaction and asynchronies. The monitor uses a signal generated by the equation of motion by using improvised values for resistance and elastance. The monitor was later tested by Kondili et al ${ }^{16}$ to quantify the inspiratory $\mathrm{P}_{\text {mus }}$, which shows an excellent estimate of $\mathrm{P}_{\text {mus }}$ calculated by the Campbell diagram of the esophageal balloon volume-pressure curve.

A recent index to quantify the inspiratory $\mathrm{P}_{\text {mus }}$ was developed by Bellani et al, ${ }^{17}$ termed the $\mathrm{P}_{\text {mus }} / \mathrm{EA}_{\mathrm{di}}$ in- 


\section{Accuracy of Ventilator Automated Respiratory Mechanics}

dex, which relates the pressure generated by the respiratory muscles $\left(\mathrm{P}_{\text {mus }}\right)$ to the electrical activity of the diaphragm $\left(\mathrm{EA}_{\mathrm{di}}\right)$. This index does not require an esophageal balloon but does require a different catheter to measure the $\mathrm{EA}_{\mathrm{di}}$, currently available on only one commercial ventilator (Servo, MAQUET, Rastatt, Germany). Conceptually, measuring the airway occlusion pressure at $0.1 \mathrm{~s}\left(\mathrm{P}_{0.1}\right)$ could be a substitute for $\mathrm{P}_{\text {mus }} . \mathrm{P}_{0.1}$ is a mechanical measurement of the output of the whole complex of the inspiratory muscles during a short occlusion at the beginning of inspiration and is expressed as a negative value of $\mathrm{cm}_{2} \mathrm{O} .{ }^{18}$ It is a very simple automatic measurement available on multiple new-generation ventilators, the occlusion can be measured the airway pressure or the esophageal pressure. This parameter has been used for the prediction of weaning from mechanical ventilation. ${ }^{19} \mathrm{P}_{0.1}$ was found to correlate well with the work of breathing and pressure-time product. Interestingly there are no studies to compare the correlation of the $\mathrm{P}_{0.1}$ measurements to actual $\mathrm{P}_{\text {mus }}$ to determine if it could be a surrogate for the more complex measurements of $\mathrm{P}_{\text {mus. }}$.

Our findings confirmed those of Iotti et al, ${ }^{5}$ who showed wide discrepancies of the respiratory dynamics measured during passive volume-controlled continuous mandatory ventilation and incremental pressure support ventilation, and concluded that the higher pressure support caused more relaxation of $\mathrm{P}_{\text {mus }}$ estimated by $\mathrm{P}_{0.1}$. Similarly, Spadaro et $\mathrm{al}^{6}$ found that the least squares fitting method performed better in neurally adjusted ventilatory assist compared with pressure support ventilation, which was attributed to more physiologic patient-ventilation interactions.

Another interesting finding was that the ventilator was not able to calculate the auto-PEEP in any of the spontaneous breaths. According to Iotti and Braschi, ${ }^{20}$ the least squares fitting method greatly underestimates the static auto-PEEP compared with measurements with the classic approach, and, hence, the evaluation of auto-PEEP seems to be the weakest point of the least squares fitting method. The worst results have been found in cases with dynamic hyperinflation.

The Hamilton G5 ventilator operator's manual includes a note disclaiming, "Actively breathing patients can create artifact or noise, which can affect the accuracy of these measurements (Available at: http://abalardx.xyz/Docs/ Resp\%20Hamilton-G5\%20Operators\%20Manual\%20180213. pdf. March 21, 2019). The more active the patient, the less accurate the measurements. To minimize patient activity during these measurements, you can choose increased pressure support by $10 \mathrm{~cm} \mathrm{H}_{2} \mathrm{O}$. After completion, return this control to its former setting." This warning underestimates the issue of the missing $\mathrm{P}_{\text {mus }}$. Increasing pressure support by $10 \mathrm{~cm} \mathrm{H}_{2} \mathrm{O}$ does not guarantee a relaxed patient with a low $\mathrm{P}_{\text {mus }}$. However, Hamilton medical has released updated software that will not display the respiratory mechanics if there are 5 consecutive patient-triggered breaths and has an additional option of turning the displayed mechanics off in the spontaneous breathing conditions.

To our knowledge, our study was the first to examine the displayed respiratory mechanics by the least squares fitting method in the adaptive support ventilation mode. As mentioned above, least square fitting method has been studied in continuous mandatory ventilation, neurally adjusted ventilatory assist, and pressure support ventilation..$^{5,6}$ The findings of the present study must be interpreted in the context of some potential limitations. The study was conducted by using a lung simulator with the inherent limitations of lung simulation. For more on ventilator simulation, we refer the readers to the editorial by Chatburn ${ }^{21}$ on simulation-based evaluation of mechanical ventilators. Our lung model was a single chamber model, which was identical to the model assumed by the ventilator in its calculations of compliance and resistance but is far less complex than the human lung in both health and disease states. The $\mathrm{P}_{\text {mus }}$ used was only inspiratory, which assumes a passive expiratory phase, which might not be the case in various conditions or asynchronies. We only selected 4 incremental $\mathrm{P}_{\text {mus }}\left(0,-5,-10,-15 \mathrm{~cm} \mathrm{H}_{2} \mathrm{O}\right)$, with constant parameters and amplitude during each breath in the experiment, whereas it might be variable in a real patient. We doubt that these limitations had any effect on the measured numbers. A limitation of the least squares fitting method itself is that it relies on a linear single-compartment model, which is the most simplified description of respiratory system mechanics, whereas the human respiratory system is definitely not linear by any means.

\section{Conclusions}

Our findings confirmed the hypothesis that the displayed automated breath-by-breath respiratory mechanics calculations were unreliable and could be misleading, especially in the actively breathing conditions. The more $\mathrm{P}_{\text {mus }}$ generated during the inspiratory cycle (more negative $\mathrm{P}_{\text {mus }}$ ), the more unreliable the calculations became, with overestimation of compliance and underestimation of resistance. The bedside clinician should not base any decision making or ventilator changes based solely on those calculations. Additional research is needed to explore different methods that would improve these calculations.

\section{REFERENCES}

1. Hess DR. Respiratory mechanics in mechanically ventilated patients. Respir Care 2014;59(11):1773-1794.

2. Lucangelo U, Bernabè $F$, Blanch L. Lung mechanics at the bedside: make it simple. Curr Opin Crit Care 2007;13(1):64-72. 


\section{Accuracy of Ventilator Automated Respiratory Mechanics}

3. Gillard C, Flémale A, Dierckx JP, Thémelin G. Measurement of effective elastance of the total respiratory system in ventilated patients by a computed method. Comparison with the static method. Intensive Care Med 1990;16(3):189-195.

4. Lucangelo U, Bernabé F, Blanch L. Respiratory mechanics derived from signals in the ventilator circuit. Respir Care 2005;50(1):55-65; discussion 65-67.

5. Iotti GA, Braschi A, Brunner JX, Smits T, Olivei M, Palo A, Veronesi R. Respiratory mechanics by least squares fitting in mechanically ventilated patients: applications during paralysis and during pressure support ventilation. Intensive Care Med 1995;21(5):406-413.

6. Spadaro S, Grasso S, Cricca1 V, Corte FD, Di Mussi R, Biondi G, et al. Comparing two different modes of mechanical ventilation by the least square fitting method: NAVA versus PSV. Intensive Care Med Exp 2015;3(Suppl 1):A319.

7. Arnal JM, Garnero A, Saoli M, Chatburn RL. Parameters for simulation of adult subjects during mechanical ventilation. Respir Care 2018;63(2):158-168.

8. Chatburn RL, El-Khatib M, Mireles-Cabodevila E. A taxonomy for mechanical ventilation: 10 fundamental maxims. Respir Care 2014; 59(11):1747-1763.

9. Hess DR, Medoff BD, Fessler MB. Pulmonary mechanics and graphics during positive pressure ventilation. Int Anesthesiol Clin 1999; 37(3):15-34.

10. Akoumianaki E, Maggiore SM, Valenza F, Bellani G, Jubran A, Loring SH, et al.; PLUG Working Group (Acute Respiratory Failure Section of the European Society of Intensive Care Medicine). The application of esophageal pressure measurement in patients with respiratory failure. Concise clinical review. Am J Respir Crit Care Med 2014;189(5):520-531.

11. Bellani G, Patroniti N, Weismann D, Galbiati L, Curto F, Foti G, Pesenti A. Measurement of pressure-time product during spontane- ous assisted breathing by rapid interrupter technique. Anesthesiology 2007;106(3):484-490.

12. Kondili E, Prinianakis G, Anastasaki M, Georgopoulos D. Acute effects of ventilator settings on respiratory motor output in patients with acute lung injury. Intensive Care Med 2001;27(7): 1147-1157.

13. Sleep-related breathing disorders in adults: recommendations for syndrome definition and measurement techniques in clinical research. Sleep 1999;22(5):667-689.

14. Jubran A, Grant BJ, Laghi F, Parthasarathy S, Tobin MJ. Weaning prediction: esophageal pressure monitoring complements readiness testing. Am J Respir Crit Care Med 2005;171(11):1252-1259.

15. Younes M, Brochard L, Grasso S, Kun J, Mancebo J, Ranieri M, et al. A method for monitoring and improving patient: ventilator interaction. Intensive Care Med 2007;33(8):1337-1346.

16. Kondili E, Alexopoulou C, Xirouchaki N, Vaporidi K, Georgopoulos D. Estimation of inspiratory muscle pressure in critically ill patients. Intensive Care Med 2010;36(4):648-655.

17. Bellani G, Mauri T, Coppadoro A, Grasselli G, Patroniti N, Spadaro $\mathrm{S}$, et al. Estimation of patient's inspiratory effort from the electrical activity of the diaphragm. Crit Care Med 2013;41(6):1483-1491.

18. Brenner M, Mukai DS, Russell JE, Spiritus EM, Wilson AF. A new method for measurement of airway occlusion pressure. Chest 1990; 98(2):421-427.

19. Sassoon CS, Te TT, Mahutte CK, Light RW. Airway occlusion pressure. An important indicator for successful weaning in patients with chronic obstructive pulmonary disease. Am Rev Respir Dis 1987;135(1):107-113.

20. Iotti GA, Braschi A. Measurements of respiratory mechanics during mechanical ventilation. Rhäzüns, Switzerland: Hamilton Medical Scientific Library, 1999;7:83-90.

21. Chatburn RL. Simulation-based evaluation of mechanical ventilators (editorial). Respir Care 2018;63(7):936-940. 